\title{
Tilt training and pacing: a report on 9 patients with neurally mediated syncope
}

\author{
Tony REYBROUCK, PhD; Hein HEIDBÜCHEL, MD, PhD; Rik WILLEMS, MD, PhD; \\ Hugo ECTOR, MD, PhD \\ Departments of Cardiology and Cardiovascular Rehabilitation, Gasthuisberg University Hospital \\ Leuven and Department of Rehabilitation Sciences, K.U.Leuven, Leuven, Belgium.
}

Objective - In patients with neurally mediated syncope (NMS), pacing has been used to prevent bradycardia and syncope. However, recurrence due to the vasodepressor component remains a problem.

Methods - We report on tilt training in 9 patients with a pacemaker (PM) implantation. Patients were submitted to daily in-hospital tilt testing. They were instructed to continue this therapy at home.

Results - A negative tilt test was obtained in all patients. Six patients remained free from syncope. Recurrent syncope was observed in 3 patients. In 4 patients the pacemaker had been implanted before the start of the tilt training programme. Five patients had a pacemaker implanted after the administration of tilt training therapy.

Conclusion - NMS also occurs in paced patients. Tilt training improves the clinical outcome by restoring the vasoconstrictor reserve capacity.

Keywords: Neurally mediated syncope - tilt training - tilt table testing - pacemaker.

\section{Introduction}

In patients with the cardioinhibitory type of syncope, the benefit from pacing has been demonstrated ${ }^{1}$. The burden of syncope was reduced but recurrence remained a problem. In the guidelines of the European Society of Cardiology, pacemaker therapy remains an indication for the cardioinhibitory or mixed carotis sinus syndrome. However, since the vasoconstrictor reserve capacity is severely reduced in patients with syncope $^{2}$, a considerable number of paced patients still suffer from syncope ${ }^{3}$. The aim of this study was to investigate: (i) if tilt training improved the clinical outcome in paced patients with syncope; (ii) the possible necessity of combining pacemaker therapy and tilt training

Address for correspondence: Prof. T. Reybrouck, Dept. of Cardiovascular Rehabilitation, Gasthuisberg University Hospital, Herestraat, B-3000 Leuven, Belgium. E-mail: tony.reybrouck@uz.kuleuven.ac.be

Received 29 September 2009; accepted for publication 2 October 2009
Patients and methods

Between 1995 and 2008, 420 patients with neurally mediated syncope underwent tilt training therapy in our department.

In this group, 9 patients had a pacemaker implanted: 4 patients before and 5 patients after the start of a tilt training programme.

All patients underwent head-up tilt testing, without pharmacological provocation. We used the Westminster protocol without cannulation as recommended by the $\mathrm{ESC}^{4}$ : a supine pre-tilt phase of at least 5 minutes. The patient was tilted at an angle of $60^{\circ}$. Time started after the patient had assumed the vertical position. Heart rate was measured from the electrocardiogram. Blood pressure was measured at the arm by an oscillometric device and was recorded every 5 minutes. The tilt test was continued until syncope, symptoms of severe orthostatic intolerance, or a total duration of $45 \mathrm{~min}$. Afterwards, the patients were returned to the horizontal position for a recovery period of 5 to 10 minutes.

After hospital discharge the patients were instructed to continue a programme of standing training: one or two 30-minute sessions per day. They had to stand with 
the upper back against a wall, without moving, their feet $15 \mathrm{~cm}$ away from the wall.

For syncope we have adopted the classification of the ESC task force report ${ }^{4}$ : (i) type 1: mixed type; (ii) type 2A: cardioinhibition without asystole; (iii) type 2B: cardioinhibition with asystole; (iv) type 3: vasodepressor response.

\section{Results}

The clinical characteristics of the patients ( 5 men and 4 women) are presented in table 1 . Age varied from 16 to 77 years. All patients had a history of recurrent syncope. In 4 patients a pacemaker had been implanted before the start of tilt training: (i) for a long episode of asystole: (case 1); (ii) for symptomatic bradycardia (case 2); (iii) for a sinus arrest of $18 \mathrm{sec}$ (case 3); (iv) for bradycardia and $30 \mathrm{sec}$ asystole (case 4). In 5 other patients a pacemaker was implanted during the follow-up period after tilt training: (i) for prolonged asystole (cases 5, 8, 9); (ii) chronotropic incompetence (case 6); (iii) second-degree atrioventricular block (case 7).

A diagnostic tilt test was positive in all patients. The time to syncope varied from 30 seconds to 35 minutes. After PM implantation, a reduction of syncope burden was observed in all patients, but recurrence was still observed in 3 patients (table 1: cases 1,2,9). With serial tilt testing (tilt training) a negative tilt test was obtained in all patients. Session 2 was the first negative test for 2 patients; session 3 for 4 patients; session 4,5 and 8 for one patient, respectively (mean 3.66; SD 1.87; median 3; interquartile range 2).

The patients were advised to continue tilt training at home. They were followed at the outpatient clinic. With the combination of tilt training and pacemaker therapy, no syncope was observed in 6/9 patients during a follow-up period of 1 year (table 1). In 3 patients recurrent syncope was still observed despite pacemaker implantation and tilt training therapy. One of them did not perform tilt training on a regular basis.

\section{Case reports}

Because of the limited number and the specific characteristics of our patients, we present the individual cases in detail.

\section{Case 1}

After pacemaker implantation for presumed sick sinus syndrome, a 40-year-old man still suffered from recurrent syncope (1/week). Daily sessions were started. The diagnostic tilt test was positive after 2 minutes. From session 2 to 8 , syncope occurred after about 2 to 3 minutes. A second series of tilt tests resulted in a negative response at the $5^{\text {th }}$ session. Tilt training was continued at home. The control tilt test 6 weeks after discharge from the hospital was normal (45 min). Three months later tilt testing remained negative. He still reported syncope recurrence (10/8 months). This was considerably better than before tilt training (1 syncope/ week).

\section{Case 2}

A 48-year-old construction worker underwent a pacemaker implantation for symptomatic bradycardia. A diagnostic tilt test was positive after 16 min with a mixed type syncope (ESC type 1). At subsequent outpatient clinic visits the patient still reported frequent dizziness. However, 10 years after pacemaker implantation, after a fall at a construction yard, he was admitted to the hospital. He reported recurrent malignant syncope. A diagnostic tilt test was positive after $16 \mathrm{~min}$ with unmeasurable blood pressure. The third consecutive tilt test became negative. Tilt training was continued at home, twice daily. During the control tilt tests syncope was no longer observed. The pacemaker was activated in the recumbent position before tilt testing, but during the tilt test a stable sinus rhythm was

Table 1. - Clinical data

\begin{tabular}{|c|c|c|c|c|c|c|c|c|}
\hline Case & Age & Gender & PM indication & PM & $\begin{array}{l}\text { PM implant: } \\
\text { before/after } \\
\text { tilt training }\end{array}$ & $\begin{array}{c}\text { Diagnostic } \\
\text { tilt test: } \\
\text { time to syncope }\end{array}$ & $\begin{array}{c}\text { First } \\
\text { negative } \\
\text { serial test }\end{array}$ & $\begin{array}{l}\text { Syncope } \\
\text { recurrence }\end{array}$ \\
\hline 1 & 40 & M & Syncope Sick sinus & DDD & before & $2 \mathrm{~min}$ & 5 & 10 in 8 months \\
\hline 2 & 48 & M & Syncope Bradycardia & VVI & before & $16 \mathrm{~min}$ & 3 & 15 in 4 years \\
\hline 3 & 46 & M & Asystole $18 \mathrm{sec}$ Sick sinus & DDD & before & $26 \mathrm{~min}$ & 2 & 0 \\
\hline 4 & 20 & $\mathrm{~F}$ & Bradycardia & DDD & before & $30 \mathrm{sec}$ & 3 & 0 \\
\hline $5^{*}$ & 61 & $\mathrm{~F}$ & Asystole & DDD & 1 year after & $5 \mathrm{~min}$ & 2 & 0 \\
\hline 6 & 61 & M & Chronotropic incompetence & DDD & 17 months after & $17 \mathrm{~min}$ & 3 & 0 \\
\hline 7 & 68 & M & $2^{\text {nd }}$ degree AVB & DDD & 2 months after & $16 \mathrm{~min}$ & 3 & 0 \\
\hline 8 & 77 & $\mathrm{~F}$ & Atrial fibrillation Asystole $7 \mathrm{sec}$ & VVI & 17 months after & $35 \mathrm{~min}$ & 4 & 0 \\
\hline 9 & 16 & $\mathrm{~F}$ & Asystole $60 \mathrm{sec}$ & DDD & 2 years after & $5 \mathrm{~min}$ & 8 & frequent \\
\hline
\end{tabular}

*Sudden death 3 years after PM implantation. This patient had continued tilt training and remained free of syncope. 
observed during all subsequent tilt tests. However, during daily life syncope recurrence was still reported periodically. This was often associated with stressful conditions.

\section{Case 3}

A 46-year-old truck driver presented with recurrent syncope. The patient was hospitalised for a diagnostic work-up. A tilt test was positive after $26 \mathrm{~min}$. This confirmed the diagnosis of neurally mediated syncope. At the time of syncope, heart rate decreased to a minimum value of 43 beats/min, followed by atrial fibrillation. Prolonged Holter monitoring revealed an episode of asystole as long as 18 seconds. A pacemaker was implanted (DDD). The patient was also advised to continue tilt training. During a follow-up period of 2 years, syncope did not occur. At control tilt testing, we have observed a normal sinus rhythm, without pacemaker activation.

\section{Case 4}

A 20-year-old female student consulted for recurrent severe syncope, since 5 years (more than twice yearly). At a regional hospital a diagnostic tilt test was positive after 30 seconds. The patient complained of severe fatigue. A pacemaker was implanted for symptomatic bradycardia. The next 3 years no syncope was reported. However, 3 years after the pacemaker implantation the patient developed syncope when working on a PC. One month later recurrent syncope was reported at school. At that time she was admitted to the hospital for initiation of tilt training therapy. The first tilt test was positive after 7 minutes, but after 2 consecutive tilt training sessions she performed a negative tilt test. During the tilt test the pacemaker was not activated. During the follow-up period extending to 12 months after discharge from the hospital, no recurrent syncope was observed and control tilt tests were normal.

\section{Case 5}

A 60-year-old woman presented at the outpatient clinic for loss of consciousness at venipuncture and other stress situations. She also fainted in the morning, when standing up. A diagnostic tilt test was positive after 5 minutes with an asysole of more than 3 seconds. She was scheduled for tilt training therapy. Already the second serial test was negative. She was discharged from the hospital and continued tilt training at home. The first control test after 6 weeks of tilt training was again positive with syncope occurring after $35 \mathrm{~min}$.
A sinus bradycardia of $48 \mathrm{bpm}$ was recorded. Tilt training was further continued at home twice daily. At the next control tilt test 2 months later, again the patient developed syncope with an asystole of 5 seconds (ESC type 2 B). Tilt training was continued. She performed a negative tilt test 3 months later. However, 6 months later she was admitted to the emergency department for a long-lasting period of asystole, witnessed by her husband but not recorded. A DDDR pacemaker was implanted. She also continued tilt training and remained free of syncope for a period of 3 years. Unfortunately, she died suddenly while on holiday: probably from a malignant arrhythmia.

\section{Case 6}

This 61-year-old man was admitted to the hospital for dizziness and syncope during exercise. A diagnostic tilt test was positive after $17 \mathrm{~min}$ with a vasodepressor response. Initally the patient underwent serial tilt training and after 2 sessions a normal tilt test was performed. The patient was discharged from the hospital and continued standing training at home. On an outpatient visit 6 weeks later he still reported dizziness during exercise. During maximal exercise the heart rate increased to 82 beats/min only (51\% of the normal value). Also the blood pressure response was abnormal: $76 / 82$ at rest and $86 / 80 \mathrm{~mm} \mathrm{Hg}$ at maximal exercise. A DDDR pacemaker was implanted. Tilt training was continued. On subsequent outpatient visits with control tilt tests the patient still reported orthostatic intolerance. One year later fludrocortisone was added to the therapy, but did not improve orthostatic tolerance. However, since the initiation of tilt training therapy, frank syncope did not occur.

\section{Case 7}

This 69-year-old woman was admitted to the emergency department of a regional hospital for syncope. She also had COPD and hypertrophic cardiomyopathy. On ECG a bifascicular block was found, but an electrophysiological study was normal. A diagnostic tilt test was positive after $16 \mathrm{~min}$. With serial tilt testing, a negative test was obtained after 2 sessions. The patient was discharged from the hospital and continued tilt training at home. However, 2 months later the patient complained of dizziness and presyncope. A control tilt test was performed which was terminated after $35 \mathrm{~min}$ because of a second-degree atrioventricular block. The patient was advised to have a pacemaker implantation and to continue tilt training. On a next control 2 months after pacemaker implantation, the patient performed a normal tilt test. During follow-up, syncope was no longer reported. 


\section{Case 8}

This woman, born in 1923, underwent CABG and aortic valve replacement in 1994. In September 2000, she was admitted to the hospital because of recurrent syncope. The diagnostic tilt test was positive after 35 min with a vasodepressor response. The $4^{\text {th }}$ consecutive tilt test became negative. However, in February 2002 the patient was diagnosed with atrial fibrillation, trifascicular block and ventricular pauses up to 7.12 sec: a definite indication for a VVIR pacemaker.

\section{Case 9}

In this 16-year-old girl with recurrent syncope, the first diagnostic tilt test resulted in an asystolic response of $60 \mathrm{sec}$ (September 2003). Serial tilt testing required 8 sessions to obtain a negative test. Because of recurrent syncope a DDD pacemaker with rate drop response was implanted in March 2006. Despite continued tilt training, trials with disopyramide, beta-blockers, fludrocortisone, sertraline, full remission could not be obtained. From March 2005 until February 2006 the patient remained almost asymptomatic. Recurrence of syncope occurred in February 2006 with a positive tilt test: asystole of $18 \mathrm{sec}$ after 7 minutes tilting. In March 2006 a pacemaker was implanted: Medtronic Enpulse DR31 with rate drop algorithm. Sporadic syncope occurred in 2006 and 2007. Pacemaker interrogation revealed frequent activation of the rate drop mechanism. Despite midodrin administration, multiple syncopal episodes occurred in December 2007. No syncope recurrence occurred between January 2008 and August 2009 while continuing tilt training. However, in August 2009 , a tilt test was positive after $14 \mathrm{~min}$, despite pacemaker activation.

\section{Discussion}

According to the guidelines of the European Society or Cardiology, pacemaker implantation is a therapeutic option for neurally mediated syncope associated with bradycardia or asystole ${ }^{4}$. Several controlled studies (VASIS, VPS, VPS2, SYDIT) have shown a reduction in the frequency of syncopal spells, but recurrent syncope has been observed in a considerable number of patients: 4.3 to $42 \%$, for a follow-up period ranging from 6 to 15 months $s^{1,3,6,7}$.

In the first VPS study, with a follow-up period of only 2 years ${ }^{6}$, syncope recurrence was still observed in more than $20 \%$ of the patients with a pacemaker vs. $70 \%$ of the patients in the control group. In the VASIS study, during 6 months of follow-up in a group of patients with recurrent syncope and a cardioinhibitory response to tilt table testing, syncope was still reported in $1 / 19$ patients with pacemaker vs. $14 / 23$ in the patients without pacemaker ${ }^{1}$. The second VPS study on 100 patients with neurally mediated syncope and a positive tilt test, reevaluated the value of pacemaker therapy in the treatment of vasovagal syncope ${ }^{3}$. In this randomized, multicentre, double-blinded study, no statistically significant benefit for pacemaker therapy could be shown. After 6 months of follow-up syncope was still reported in $40 \%(25-52 \% \mathrm{CL})$ of the patients with pacemaker without active pacing (ODO), vs. 31\% $(17-43 \% \mathrm{CL})$ in the group with active pacing (DDD) ${ }^{3}$. The SYDIT study, a multicenter, randomized and controlled trial on the efficacy of pacing in patients with recurrent syncope in 93 patients during a follow-up period of 390 days found a significant effect in favour of pacing compared to medical treatment ${ }^{7}$. However, recurrent syncope was observed in 2 patients $(4.3 \%)$ in the pacemaker group, compared to $25 \%$ in the patients with medical treatment. Finally, the ISSUE 2 study showed that pacing may be effective when asystole is documented, but there is no rationale for pacing in patients without a documented bradycardia ${ }^{8}$. Taken together, these studies show that in the majority of patients syncope recurrence decreases after pacemaker implantation, but the recurrence rate remains high. In some patients pacemaker therapy may delay the onset of syncope, which could allow the patient to take preventive measures.

Although patients with a cardioinhibitory type of syncope show bradycardia ${ }^{8}$, a vasodilatatory component has also been observed during beat-to-beat blood pressure measurements. This may explain why these patients may still develop syncope despite pacemaker implantation ${ }^{3}$.

In our department tilt training has been applied successfully in patients with neurally mediated syncope, because it restores the disturbed autonomic balance both with vasodilatatory and cardioinhibitory components $^{2,8}$. The rationale for tilt training is that repeated daily tilt testing improves the impaired orthostatic tolerance by increasing the degree of vasomotor reserve available for vasoconstriction ${ }^{2}$.

In this paper we report the value of tilt training in patients with pacemaker implantation. In this series 4 of the 9 patients had a pacemaker implanted before tilt training. However, in all 4 patients recurrent syncope was still observed after pacemaker implantation. Tilt training prevented syncope recurrence in 2 and reduced syncope burden in 2 other individuals. In the other 5 patients, after the initiation of tilt training, a pacemaker was inserted for development of AV block in one patient, prolonged asystole in 3 patients, chronotropic incompetence in one patient.

In this series, 6 out of 9 patients were free of syncope when tilt training was continued for a period of 12 months. Recurrent syncope was observed in the 
other 3, but the burden of syncope was reduced after combined pacemaker and tilt training therapy.

A negative tilt test could be obtained in all patients after serial tilt testing. The number of sessions to reach a first negative tilt test (mean 3.66; SD 1.87; median 3; interquartile range 2) is somewhat higher than in patients with neurally mediated syncope without pacemaker implantation $(2.9 \pm 1.3 \text { sessions })^{9}$. The patients started this tilt training programme in the hospital and were instructed to continue standing training at home. Patients were followed at the outpatient clinic with control tilt tests, to improve patient compliance. In other series where patients performed tilt training immediately at home or without clinical follow-up, the compliance to therapy decreases very rapidly. In a study on the efficacy of tilt training performed at home, Foglia-Manzillo reported that, at follow-up after 1 year, only $5(17 \%)$ of a series of 29 patients had continued tilt training ${ }^{10}$. We are convinced that starting tilt training in the hospital in a controlled setting, with regular outpatient control tests avoids this high drop-out rate.

It is well known that the type of syncope can change during subsequent tilt tests 9 . Furthermore there is a high recurrence rate of syncope in patients with the cardioinhibitory type of NMS treated with pacemaker therapy ${ }^{3}$. In patients with the cardioinhibitory type of neurally mediated syncope, beat-to-beat measurements of heart rate and blood pressure have shown that these patients have a reduced vasoconstrictor reserve capacity, emphasizing the mixed pathophysiology of syncope even if the cause seems purely bradycardic ${ }^{2}$.

The complexity of neurally mediated syncope is also illustrated by the variety of therapeutic options that have been described for this disorder ${ }^{4,11}$ such as increased fluid intake, plasma volume expansion by mineralo-corticoids or vagolytic drugs. A recent randomized study on 125 consecutive patients confirms the value of orthostatic training in the prevention of syncope $^{12}$.

Our experience illustrates that: (i) tilt training can be indicated for patients with pacemakers and a persisting problem of recurrent syncope; (ii) in patients with neurally mediated syncope, we must remain aware of emerging indications for cardiac pacing; (iii) we have to accept that no treatment will ever prevent the last syncope in every patient; (iv) syncope is a logical complication of the upright position of mankind.

\section{References}

1. Sutton R, Brignole M, Menozzi C, Raviele A, Alboni P, Giani P, Moya A. Dual chamber pacing in the treatment of neutrally mediated tilt-positive cardio-inhibitory syncope. Circulation 2000; 102: 294-5.
2. Verheyden, B, Ector H, Aubert A, Reybrouck T. Tilt training increases the vasoconstrictor reserve in patients with neurally mediated syncope evoked by head-up tilt testing. Eur Heart J 2008; 298: 523-30.

3. Connolly SJ, Sheldon R, Thorpe KE, Roberts RX, Ellenbogen KA, Wilkoff BL, Morillo C, Gent M, VPS II Investigators. Pacemaker therapy for prevention of syncope in patients with recurrent severe vasovagal syncope: Second Vasovagal Pacemaker Study (VPS II): a randomized trial. JAMA 2003; 289: 2224-9.

4. Brignole M, Alboni P, Benditt D, Bergfeldt L, Blanc JJ, Block Thomsen PE, van Dijk JC, Fitzpatrick A, Hohnloser S, Janousek J, Kapoor W, Kenny R, Kulakowski P, Masotti G, Moya A, Raviele A, Sutton R, Theodorakis G, Ungar A, Wieling W. Guidelines on management (diagnosis and Treatment) of syncope. Eur Heart J 2004; 25: 2054-72.

5. Vahanian A, Auricchio A, Bax J, Ceconi C, Dean V, Despres C, Filippatos G, Funck-Brentano C, Hobbs R, Kearney P, McDonagh T, McGregor K, Popescu B, Reiner Z, Sechtem U, Sirnes PA, Tendera M, Vardas P, Widimsky, Zamorano Gomez JL. ESC Committee for practice guidelines (CPG2006-2008). Lippincott Williams \& Wilkins, London, 2008.

6. Connolly SJ, Sheldon R, Roberts RS, Gent M. The North American Vasovagal Pacemaker Study (VPS). A randomized trial of permanent pacing for the prevention of vasovagal syncope. J Am Coll Cardiol 1999; 33: 16-20.

7. Ammirati F, Coivicchi F, Santini M. Syncope Diagnosis and Treatment Study Investigators. Permanent cardiac pacing versus medical treatment for the prevention of recurrent vasovagal syncope. A multicenter, randomized, controlled trial. Circulation 2001; 104; 52-7.

8. Brignole M, Sutton R, Menozzi C, Garcia-Civera R, Moya A, Wieling W, Andresen D, Benditt D, Vardas P (ISSUE 2 Group). Early application of an implantable loop recorder allows specific therapy in patients with recurrent neurally mediated syncope. Eur Heart J 2006; 27: 1085-92.

9. Ector H, Willems R, Heidbüchel H, Reybrouck T. Repeated tilt testing in patients with tilt-positive neurally mediated syncope. Europace 2005; 7: 628-33.

10. Foglia-Manzillo G, Giada F, Gagglioli G, Bartoletti A, Lolli G, Dinelli M, Del Rosso A, Santorone M, Raviele A, Brignole M. Efficacy of tilt training in the treatment of neurally mediated syncope. A randomized study. Europace 2004; 6: 199-204.

11. Reybrouck T, Ector H. Tilt training: a new challenge in the treatment of neurally mediated syncope. Acta Cardiol 2006; 61: $183-9$.

12. Zeng H, Ge K, Zhang W, Wang G, Guo L. The effect of orthostatic training in the prevention of vasovagal syncope and its influencing factors. Int Heart $J$ 2008; 49: 707-12. 